Short communication

\title{
Nanoparticle mucoadhesive system as a new tool for fish immune system modulation
}

\author{
Ives Charlie-Silva ${ }^{a}$, Nathalie Ferreira Silva de Melo ${ }^{b}$, Juliana M.M. Gomes ${ }^{c}$, \\ André Luis Branco de Barros ${ }^{\mathrm{f}}$, José Dias Corrêa Junior ${ }^{\mathrm{c}, *}$

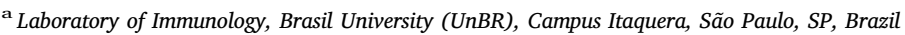 \\ ${ }^{\mathrm{b}}$ Department of Immunology and Biochemistry, Faculty of Medicine São Leopoldo Mandic, Araras, SP, Brazil \\ ${ }^{\mathrm{c}}$ Department of Morphology, ICB-UFMG, Belo Horizonte, MG, Brazil \\ d São Paulo State University (UNESP), Institute of Science and Technology of Sorocaba, Sorocaba, SP, Brazil \\ e Aquiculture Laboratory (Laqua), UFMG, Belo Horizonte, MG, Brazil \\ ${ }^{\mathrm{f}}$ Department of Clinical and Toxicological Analyses, Faculty of Pharmacy-UFMG, Belo Horizonte, MG, Brazil
} Leonardo Fernandes Fraceto ${ }^{\mathrm{d}}$, Daniela Chemim de Melo ${ }^{\mathrm{e}}$, Juliana de Oliveira Silva ${ }^{\mathrm{f}}$,

\section{A R T I C L E I N F O}

\section{Keywords:}

Nanodelivery

Chitosan-coated PLGA nanoparticles

Mucoadhesive nanoparticles

Immunomodulators

\begin{abstract}
A B S T R A C T
Recently, chitosan-based nanoparticles with mucoadhesive properties emerged as a strategy for mucosal drug release. This study aimed to characterize the interaction of mucoadhesive system chitosancoated PLGA nanoparticles (NPMA) with fish external mucus. NP suspensions with fluorescent probe were prepared and characterized by size, polydispersity, zeta potential and $\mathrm{pH}$ measures. In post-exposure fish were observed an increase in fluorescence imaging over time and it was significantly influenced by NPMA concentration. We also observed the main predominance the fluorescence in the spleen, followed by liver, gill and other tissues. The use of mucoadhesive nanocarriers becomes an alternative for administration of drugs and immunomodulators in immersion systems since the nanosystem can adhere to the mucosal surface of the fish with little residual effect in the water.
\end{abstract}

Nanoparticle-based drug delivery systems (NDDS) have been developed to prolong and optimize drug administration and decrease toxicity in several specific applications [1,2]. Many studies have demonstrated advantages of using NDDS in comparison with the conventional formulations by improving pharmacokinetics and bioavailability of drugs and reducing their side effects [1,3]. Among the various materials available for drug delivery, we can highlight poly (D, L-lactide-co-glycolide) (PLGA), which has high safety and excellent characteristics, such as biocompatibility, biodegradability, and absence of toxicity [4]. In addition, the U.S. Food and Drug Administration has approved its use in veterinary and human medicine [5]. Several studies have used PLGA nanoparticles as drug delivery carriers to modulate and improve the fish immune system [6-10]. Recently, the use of nanoparticles with mucoadhesive properties has emerged as a strategy for mucosal drug release. Chitosan-coated nanoparticles have attracted interest because of their ability to interact electrostatically with the mucosa and increase permeation due to the reorganization of intercellular junctions and interference in the lipid deposition of the epithelium in mammals [11]. Some studies have described the use of chitosan micro and nanoparticles in supplemented diets to improve immunological defense of fish [12,13]. In addition, another study reported that mucoadhesive properties help to model drug release by achieving slow drug leakage [14]. Chitosan nanoparticles have been used for the delivery of vitamin C [15], RNA [16], bacterial antigens [17] and plasmid DNA [18,19]. The use of intraperitoneal (IP) immunomodulators is very effective in fish but is very labor intensive and expensive. The use of modulators by immersion or bath causes absorption in the skin, gills and intestine (through drinking) and is the most frequently adopted method, particularly in the case of younger fish [20]. In aquaculture, the main problem of the efficacy of immunomodulators is related to the form of exposure (intraperitoneal or immersion) and their absorption, which is highly variable and dosedependent, possibly leading to reduction in the drug's bioavailability. The aim of this study was to characterize the interaction of a mucoadhesive system of chitosan-coated PLGA nanoparticles (NPMA) with fish external mucus.

For the experiment, 40 zebrafish (4 months old), with circa $0.5 \mathrm{~g}$ each one, from the same spawning batch, were obtained from the

\footnotetext{
* Corresponding author.

E-mail address: correajr@ufmg.br (J.D. Corrêa).
} 
Aquaculture Laboratory (Laqua) of the Veterinary School of Minas Gerais Federal University (UFMG), Brazil. After transportation, the animals were acclimatized for 15 days and stored in an aquarium with capacity of $2 \mathrm{~L}$, following the maintenance standards established by Westerfield (2007) [21]. The study was approved by the ethics committee of Minas Gerais Federal University (CEUA-UFMG, 336/2017). Water quality remained within the parameters appropriate for the species $\left(\mathrm{OD}=6.0 \pm 0.123 \mathrm{mg} \mathrm{L}^{-1}: \mathrm{pH}=7.2 \pm 0.78\right.$ and electrical conductivity $=110.10 \pm 10.305 \mu \mathrm{sm}^{-1}$ ) [21].

The nanoparticles synthesis was performed according to the interfacial polymer deposition method [22]. The organic phase was composed of PLGA polymer (50:50) (Sigma ${ }^{\star}$ ), sorbitan monostearate (Sigma ${ }^{\circ}$ ), medium chain triglyceride (Chemspecs ${ }^{\circ}$ ), fluorescent probe (1,2-distearoyl-sn-glycero-3-phosphoethanolamine- $N$-(7-nitro-2,1,3benzoxadiazol-4-yl) ammonium salt) (Avanti ${ }^{\circ}$ ) and acetone. The organic phase was poured under magnetic stirring into the aqueous phase composed of polysorbate 80 (Sigma ${ }^{\circ}$ ) and deionized water and was kept under magnetic stirring for $10 \mathrm{~min}$. The organic solvent was removed under reduced pressure. A solution of low molecular weight chitosan $\left(5 \mathrm{mg} \mathrm{mL}^{-1}\right.$ ) was added to the nanoparticle suspensions with magnetic stirring for $1 \mathrm{~h}$ for coating [22,23].

Size, polydispersity index, and zeta potential were measured by photon correlation spectroscopy. These measurements were performed by diluting nanoparticle suspensions with water (Milli-Q) followed by analysis in a Zetasizer Nano ZS 90 particle analyzer (Malvern) at $25^{\circ} \mathrm{C}$. Each result was expressed as the average of three repetitions [24]. Nanoparticle tracking analysis (NTA) was used to obtain concentration and size distribution. The suspensions were diluted and analyzed with a Nanosight LM 10 apparatus (Malvern) using a volumetric cell, $532 \mathrm{~nm}$ laser wavelength and CMOS camera. The videos were analyzed with the NanoSight 2.3 software. Each replicate consisted of five measurements with about 2000 particles counted in each analysis [25].

The nanoparticles' adherence to mucous was first evaluated using aliquots of NPMA (at $1.5 \times 10^{17}$ and at $7.6 \times 10^{14}$ particles $/ \mathrm{mL}^{-1}$ ) added to $2 \mathrm{mg}$ of mucus and water of, whose had their absorbance values read between wavelengths of 200 and $1000 \mathrm{~nm}$ in a Varioskan Multi Reader (Thermo). In vivo fluorescence images of zebrafish were collected with a Bruker Xtreme In-Vivo Imaging System (Bruker) equipped with a back-illuminated 4 megapixel camera.

In the in vivo assays, the evaluation of the NPMA exposure was performed immersing the fish after fasting for $24 \mathrm{~h}$. The experiment was composed of four treatments: T1: naïve control; T2: exposure to NP; and T3 and T4: exposure to two different NPMA concentrations. Zebrafish were assayed in beakers containing $80 \mathrm{~mL}$ of water from the aquarium for $5 \mathrm{~min}$ in an aqueous solution containing either non-mucoadhesive nanoparticles (NP) (at $1.5 \times 10^{17}$ particles. $\mathrm{mL}^{-1}$ ) (T2) or NPMA (at $1.5 \times 10^{17}$ or $7.6 \times 10^{14}$ particles.mL ${ }^{-1}$ ) (T3 and T4, respectively). No nanoparticles were added to the control group (T1).

Each group contained 10 replicates - each animal was considered a repetition and 20 replicates were performed for each treatment. After exposure, the fish were transferred to a $500 \mathrm{~mL}$ beaker containing clean water. For each treatment, water $(5 \mathrm{~mL})$ and fish $(\mathrm{n}=10)$ were sampled and frozen at $-80^{\circ} \mathrm{C}$ at $0,30,60$ and $180 \mathrm{~min}$.

Chitosan-coated PLGA nanoparticles were prepared, the suspensions were characterized with respect to size, polydispersity, zeta potential and $\mathrm{pH}$. The initial colloidal parameters are described in Table 1.

The mean diameters and polydispersity index of the NP were compatible with those commonly found for polymeric nanosystems studied previously [26-28]. There was an increase in diameter of NPMA, providing evidence of coating formation with no aggregation of nanoparticles [23]. The polydispersity index values were below 0.2 for both nanoparticles and indicated homogeneous particle diameter distribution.

The zeta potential values obtained for NPs showed negative values due to the components of the formulation of surfactants and the polymer, which has carboxyl groups in its structure. The addition of
Table 1

Values of mean diameter (nm), polydispersity index, zeta potential, $\mathrm{pH}$ and particle concentration for suspensions of PLGA nanocapsules with and without chitosan coating.

\begin{tabular}{lllll}
\hline Nanocarrier & $\begin{array}{l}\text { Mean diameter (nm); } \\
\text { (polydispersity index) }\end{array}$ & $\begin{array}{l}\text { Zeta } \\
\text { potential } \\
(\mathrm{mV})\end{array}$ & $\mathrm{pH}$ & $\begin{array}{l}\text { Concentration } \\
\left.\text { (particles } / \mathrm{mL}^{-1}\right)\end{array}$ \\
\hline NP & $201.6 ;(0.145)$ & -19.2 & 3.61 & $1.45 \times 10^{17}$ \\
NPMA & $291.1 ;(0.189)$ & +44.1 & 3.97 & $1.52 \times 10^{17}$ \\
\hline
\end{tabular}

polysaccharide promoted changes in zeta potential to positive values due to the presence of positively charged amino groups in the chitosan, indicating the coating of the NP surface. Similar results were found for chitosan-coated polymeric and zein nanoparticles [23,29].

After exposure of zebrafish, we observed an increase in fluorescence imaging with time, which was significantly influenced by NPMA concentration. The highest concentration tested $\left(1.52 \times 10^{15}\right.$ particles/ $\mathrm{mL}^{-1}$ ) resulted in the greatest fluorescence intensity in $\mathrm{p} / \mathrm{s} / \mathrm{mm}^{2}$ at 60 and $180 \mathrm{~min}$. We also measured the intensity of in vivo fluorescence at 0, 30, 60 and $180 \mathrm{~min}$ after exposure to the NPMA. We found a level below $65 \mathrm{p} / \mathrm{s} / \mathrm{mm}^{2}$ with peak at $60 \mathrm{~min}$ with $138 \mathrm{p} / \mathrm{s} / \mathrm{mm}^{2}$ for $7.6 \times 10^{14}$ particles $/ \mathrm{mL}^{-1}$. Fig. 1 shows the percentages of fluorescence obtained as a function of the concentrations of nanoparticles to which the animals were exposed. The lowest concentration, $\left(7.6 \times 10^{14}\right.$ particles $/ \mathrm{mL}^{-1}$ ) presented higher initial values, which decreased over time at 60 and $180 \mathrm{~min}$, correlated with the increase of NPMA presence in pure water. No mortality was observed after exposure to mucoadhesive nanoparticles at the concentrations tested. In addition, for the evaluation of fluorescence in the tissue, fragments of gills, stomach, liver, and spleen were collected. For histological analysis, $6 \mu \mathrm{m}$ thick sections were mounted on slides for observation of the general cell structures with a fluorescence microscope. This revealed the predominance of fluorescence in the spleen, followed by liver, gill and other tissues.

We measured the green fluorescent probe at $460 \mathrm{~nm}$ of $1.52 \times 10^{15}$ and $7.6 \times 10^{14}$ particles $/ \mathrm{mL}^{-1}$ after $0,30,60$ and $180 \mathrm{~min}$ in clear water. It was observed an increase of the fluorescence intensity in pure water as a function of time and nanoparticle concentration. At both concentrations, a significant increase in the absorbance of NPMA was observed, which presented the highest probe concentration $\left(1.52 \times 10^{15}\right.$ particles $\left./ \mathrm{mL}^{-1}\right)$ at all times evaluated in relation to the lowest concentration $\left(7.6 \times 10^{14}\right.$ particles $\left./ \mathrm{mL}^{-1}\right)$. This increased over time, with peak at $180 \mathrm{~min}$ after exposure to the highest concentration $\left(1.52 \times 10^{15}\right.$ particles $\left./ \mathrm{mL}^{-1}\right)$. In contrast, in the animals exposed to the lowest concentration, the peak occurred at $30 \mathrm{~min}$ when evaluating the exposure time, followed by a decrease in the concentration $(\mu \mathrm{g})$ in pure water after 60 and $180 \mathrm{~min}$ of exposure.

Fish produce substances that serve as important physical barriers [30]. This is a complex viscous secretion called mucus, which covers the epithelial cells [31]. Its functional properties depend on the ability to form a gel on the epithelial surface [32]. In addition, mucus is part of the host defense system and associated with osmoregulation [33-35]. The outer surface of the zebrafish is rich in mucus, which acts as one of the innate defense mechanisms. This mucus contains mucin (a high molecular weight glycoprotein) in addition to other proteins, ions, and lipids, giving viscoelastic and adhesive properties as well as protection. It can change in composition (an increase of the glycosylation index) with increases of bacterial load in water [31,36]. These mucosal properties can be exploited for controlled drug release and immunomodulation.

The increase in fluorescence as a function of time showed that NPMA had the ability to bind to the zebrafish surface even after the animals were transferred to water without NPMA. This phenomenon can be attributed to the electrostatic interaction between the cationic amino groups of chitosan and the strongly anionic regions of mucus, 
A
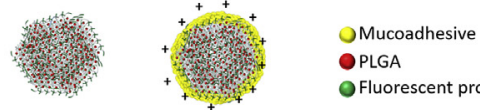

OPLGA

OFluorescent probe
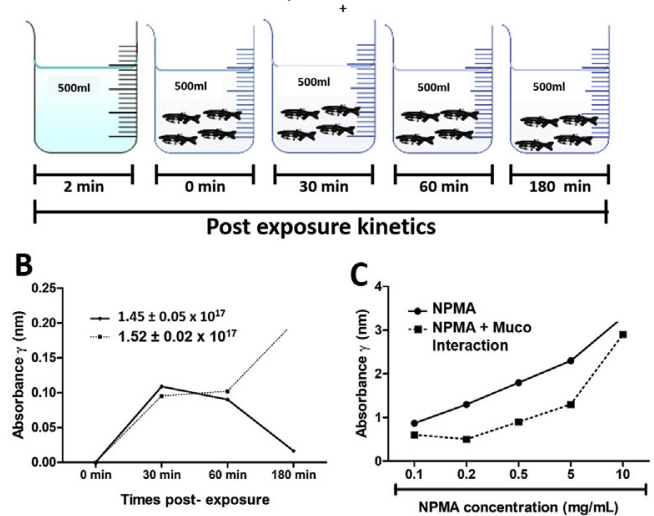

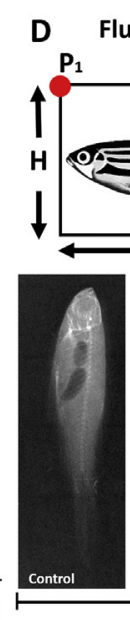

Fig. 1. Nanodelivery mucoadhesive system in zebrafish. A - Experimental design of zebrafish exposure to mucoadhesive $\mathrm{B}$ and $\mathrm{C}$ - Absorption spectra of pure water and NPMA and mucus $(2 \mathrm{mg}) \mathrm{D}-$ Green fluorescence image of zebrafish at different exposure times. $*\left(\mathrm{p} / \mathrm{s} / \mathrm{mm}^{2}\right)=$ photon/ second/millimeter ${ }^{2}$. (For interpretation of the references to colour in this figure legend, the reader is referred to the Web version of this article.) which is rich in carboxylic acids [14].

The results of this study showed for the first time the interaction and adhesion of chitosan-coated PLGA nanoparticles in the external mucus layer of zebrafish. Nonetheless, there is still a predilection of these nanoparticles for the spleen of zebrafish, clearly demonstrating the interaction with this organ, which has lymphoid function and the important immunological function of producing antibodies. The use of mucoadhesive nanocarriers is an alternative for administration of drugs and immunomodulators in immersion systems since the nanosystem can adhere to the mucosal surface of the fish with little residual effect on the water.

\section{Acknowledgments}

We thank the Brazilian research support agencies CNPq, process 301473/2016-1 and FAPEMIG, number APQ-02913-17.

\section{References}

[1] V.P. Torchilin, Multifunctional, stimuli-sensitive nanoparticulate systems for drug delivery, Nat. Rev. Drug Discov. 13 (2014) 813-827, https://doi.org/10.1038/ nrd4333.

[2] Y.-F. Wang, L. Liu, X. Xue, X.-J. Liang, Nanoparticle-based drug delivery systems: what can they really do in vivo? F1000Research 6 (2017), https://doi.org/10. 12688/f1000research.9690.1.

[3] N.P. Aditya, P.G. Vathsala, V. Vieira, R.S.R. Murthy, E.B. Souto, Advances in nanomedicines for malaria treatment, Adv. Colloid Interface Sci. 201-202 (2013) 1-17, https://doi.org/10.1016/j.cis.2013.10.014.

[4] H.K. Makadia, S.J. Siegel, Poly lactic-co-glycolic acid (PLGA) as biodegradable controlled drug delivery Carrier, Polymers 3 (2011) 1377-1397, https://doi.org/ 10.3390/polym3031377.

[5] M. Shaalan, M. Saleh, M. El-Mahdy, M. El-Matbouli, Recent progress in applications of nanoparticles in fish medicine: a review, Nanomed. Nanotechnol. Biol. Med. 12 (2016) 701-710, https://doi.org/10.1016/j.nano.2015.11.005.

[6] B.N. Fredriksen, K. Sævareid, L. McAuley, M.E. Lane, J. Bøgwald, R.A. Dalmo, Early immune responses in Atlantic salmon (Salmo salar L.) after immunization with PLGA nanoparticles loaded with a model antigen and $\beta$-glucan, Vaccine 29 (2011) 8338-8349, https://doi.org/10.1016/j.vaccine.2011.08.087.

[7] J. Tian, J. Yu, Poly(lactic-co-glycolic acid) nanoparticles as candidate DNA vaccine Carrier for oral immunization of Japanese flounder (Paralichthys olivaceus) against lymphocystis disease virus, Fish Shellfish Immunol. 30 (2011) 109-117, https:// doi.org/10.1016/j.fsi.2010.09.016.

[8] B.N. Fredriksen, J. Grip, PLGA/PLA micro- and nanoparticle formulations serve as antigen depots and induce elevated humoral responses after immunization of Atlantic salmon (Salmo salar L.), Vaccine 30 (2012) 656-667, https://doi.org/10. 1016/j.vaccine.2011.10.105.

[9] L.B. Hølvold, B.N. Fredriksen, J. Bøgwald, R.A. Dalmo, Transgene and immune gene expression following intramuscular injection of Atlantic salmon (Salmo salar L.) with DNA-releasing PLGA nano- and microparticles, Fish Shellfish Immunol. 35 (2013) 890-899, https://doi.org/10.1016/j.fsi.2013.06.030.

[10] P.R. Rauta, B. Nayak, Parenteral immunization of PLA/PLGA nanoparticle encapsulating outer membrane protein (Omp) from Aeromonas hydrophila: evaluation of immunostimulatory action in Labeo rohita (rohu), Fish Shellfish Immunol. 44 (2015) 287-294, https://doi.org/10.1016/j.fsi.2015.02.007.

[11] A. Sosnik, M. Menaker Raskin, Polymeric micelles in mucosal drug delivery: challenges towards clinical translation, Biotechnol. Adv. 33 (2015) 1380-1392, https://doi.org/10.1016/j.biotechadv.2015.01.003.

[12] B. Sun, H. Quan, F. Zhu, Dietary chitosan nanoparticles protect crayfish Procambarus clarkii against white spot syndrome virus (WSSV) infection, Fish Shellfish Immunol. 54 (2016) 241-246, https://doi.org/10.1016/j.fsi.2016.04.009.

[13] T. Behera, P. Swain, Alginate-chitosan-PLGA composite microspheres induce both innate and adaptive immune response through parenteral immunization in fish, Fish Shellfish Immunol. 35 (2013) 785-791, https://doi.org/10.1016/j.fsi.2013.06. 012 .

[14] A.C. da S. Costa, H.M. Brandão, S.R. da Silva, A.R. Bentes-Sousa, J. a. P. Diniz, J. de J. Viana Pinheiro, M. de F.C. de Melo, J.O.C. Silva, E.R. Matos, R.M. Ribeiro-Costa, Mucoadhesive nanoparticles: a new perspective for fish drug application, J. Fish. Dis. 39 (2016) 503-506, https://doi.org/10.1111/jfd.12373.

[15] A. Alishahi, A. Mirvaghefi, M.R. Tehrani, H. Farahmand, S. Koshio, F.A. Dorkoosh, M.Z. Elsabee, Chitosan nanoparticle to carry vitamin $C$ through the gastrointestinal tract and induce the non-specific immunity system of rainbow trout (Oncorhynchus mykiss), Carbohydr. Polym. 86 (2011) 142-146, https://doi.org/10.1016/j. carbpol.2011.04.028.

[16] S. Ferosekhan, S. Gupta, A.R. Singh, M. Ashraf Rather, R. Kumari, D.C. Kothari, A. Kumar Pal, S. Balkrishna Jadhao, RNA-Loaded chitosan nanoparticles for enhanced growth, immunostimulation and disease resistance in fish, Curr. Nanosci. 10 (2014) 453-464.

[17] L. León-Rodríguez, A. Luzardo-Álvarez, J. Blanco-Méndez, J. Lamas, J. Leiro, Biodegradable microparticles covalently linked to surface antigens of the scuticociliate parasite $\mathrm{P}$. dicentrarchi promote innate immune responses in vitro, Fish Shellfish Immunol. 34 (2013) 236-243, https://doi.org/10.1016/j.fsi.2012.10.029.

[18] S. Rajesh Kumar, V.P. Ishaq Ahmed, V. Parameswaran, R. Sudhakaran, V. Sarath Babu, A.S. Sahul Hameed, Potential use of chitosan nanoparticles for oral delivery of DNA vaccine in Asian sea bass (Lates calcarifer) to protect from Vibrio (Listonella) anguillarum, Fish Shellfish Immunol. 25 (2008) 47-56, https://doi.org/ 10.1016/j.fsi.2007.12.004.

[19] L. Li, S.-L. Lin, L. Deng, Z.-G. Liu, Potential use of chitosan nanoparticles for oral delivery of DNA vaccine in black seabream Acanthopagrus schlegelii Bleeker to protect from Vibrio parahaemolyticus, J. Fish. Dis. 36 (2013) 987-995, https://doi. org/10.1111/jfd.12032.

[20] J.H.W.M. Rombout, G. Yang, V. Kiron, Adaptive immune responses at mucosal surfaces of teleost fish, Fish Shellfish Immunol. 40 (2014) 634-643, https://doi. $\operatorname{org} / 10.1016 /$ j.fsi.2014.08.020.

[21] M. Westerfield, The Zebrafish Book. A Guide for the Laboratory Use of Zebrafish (Danio rerio), fifth ed., University of Oregon Press, Eugene, 2007.

[22] H. Fessi, F. Puisieux, J.P. Devissaguet, N. Ammoury, S. Benita, Nanocapsule formation by interfacial polymer deposition following solvent displacement, Int. J. Pharm. (1989), https://doi.org/10.1016/0378-5173(89)90281-0.

[23] R. Grillo, A.H. Rosa, L.F. Fraceto, Poly( $\varepsilon$-caprolactone) nanocapsules carrying the herbicide atrazine: effect of chitosan-coating agent on physico-chemical stability and herbicide release profile, Int. J. Environ. Sci. Technol. 11 (2014) 1691-1700, https://doi.org/10.1007/s13762-013-0358-1.

[24] N.F.S. de Melo, E.V.R. Campos, C.M. Gonçalves, E. de Paula, T. Pasquoto, R. de Lima, A.H. Rosa, L.F. Fraceto, Development of hydrophilic nanocarriers for the charged form of the local anesthetic articaine, Colloids Surf. B Biointerfaces 121 (2014) 66-73, https://doi.org/10.1016/j.colsurfb.2014.05.035.

[25] W. Anderson, D. Kozak, V.A. Coleman, A..K. Jämting, M. Trau, A comparative study of submicron particle sizing platforms: accuracy, precision and resolution analysis of polydisperse particle size distributions, J. Colloid Interface Sci. 405 (2013) 322-330, https://doi.org/10.1016/j.jcis.2013.02.030.

[26] C.M. Moraes, A.P. de Matos, E. de Paula, A.H. Rosa, L.F. Fraceto, Benzocaine loaded biodegradable poly-(d,l-lactide-co-glycolide) nanocapsules: factorial design and characterization, Mater. Sci. Eng. B 165 (2009) 243-246, https://doi.org/10.1016/ j.mseb.2009.06.011.

[27] N.F.S. de Melo, R. Grillo, V.A. Guilherme, D.R. de Araujo, E. de Paula, A.H. Rosa, L.F. Fraceto, Poly(lactide-co-glycolide) nanocapsules containing benzocaine: 
influence of the composition of the oily nucleus on physico-chemical properties and anesthetic activity, Pharm. Res. (N. Y.) 28 (2011) 1984-1994, https://doi.org/10. 1007/s11095-011-0425-6.

[28] N.F. Silva De Melo, D.R. De Araújo, R. Grillo, C.M. Moraes, A.P. De Matos, E. de Paula, A.H. Rosa, L.F. Fraceto, Benzocaine-Loaded polymeric nanocapsules: study of the anesthetic activities, J. Pharmacol. Sci. 101 (2012) 1157-1165, https://doi.org/ 10.1002/jps.22829.

[29] C.-E. Park, D.-J. Park, B.-K. Kim, Effects of a chitosan coating on properties of retinol-encapsulated zein nanoparticles, Food Sci. Biotechnol 24 (2015) 1725-1733, https://doi.org/10.1007/s10068-015-0224-7.

[30] F.A. Guardiola, P. Logothetis, J. Meseguer, M.A. Esteban, Evaluation of silver nanospheres on viability and innate cellular parameters of gilthead seabream (Sparus aurata L.) head-kidney leucocytes, Fish Shellfish Immunol. 69 (2017) 99-107, https://doi.org/10.1016/j.fsi.2017.08.017.

[31] M. van der Marel, N. Caspari, H. Neuhaus, W. Meyer, M.-L. Enss, D. Steinhagen, Changes in skin mucus of common carp, Cyprinus carpio L., after exposure to water with a high bacterial load, J. Fish. Dis. 33 (2010) 431-439, https://doi.org/10. 1111/j.1365-2761.2010.01140.x.

[32] S. Bragadeesw, S. Thangaraj, Hemolytic and antibacterial studies on skin mucus of eel fish, Anguilla anguilla linnaues, 1758, Asian J. Bio. Sci. 4 (2011) 272-276, https://doi.org/10.3923/ajbs.2011.272.276.

[33] S. Jakowska, Mucus secretion in fish-a note, Ann. N. Y. Acad. Sci. 106 (1963) 458-462.

[34] M.W. Rosen, N.E. Cornford, Fluid friction of fish slimes, Nature 234 (1971), https:// doi.org/10.1038/234049a0 234049a0.

[35] M.F. Brinchmann, Immune relevant molecules identified in the skin mucus of fish using -omics technologies, Mol. Biosyst. 12 (2016) 2056-2063, https://doi.org/10. 1039/c5mb00890e.

[36] D. Gomez, J.O. Sunyer, I. Salinas, The mucosal immune system of fish: the evolution of tolerating commensals while fighting pathogens, Fish Shellfish Immunol. 35 (2013) 1729-1739, https://doi.org/10.1016/j.fsi.2013.09.032. 